\title{
Uterine flexion suture: modified B-Lynch uterine compression suture for the treatment of uterine atony during cesarean section
}

This article was published in the following Dove Press journal: International Journal of Women's Health

\author{
Srisuda Songthamwat \\ Metha Songthamwat \\ Department of Obstetrics and \\ Gynecology, Udonthani Hospital, \\ Udonthani, Thailand
}

Correspondence: Metha Songthamwat Department of Obstetrics and Gynecology, Udonthani Hospital, Udonthani 41000, Thailand

Tel +66815451499

Email methal499@gmail.com
Objective: The aim of this study was to report our clinical experience of applying a uterine flexion suture, which was modified from the B-Lynch uterine compression suture, for treating uterine atony during cesarean section.

Materials and methods: This is a retrospective descriptive study describing the use of a new technique, uterine flexion suture, for treating uterine atony during cesarean section. The study period was from January 2009 to December 2017 at Udonthani Hospital, Udonthani, Thailand. Uterine atony during cesarean section was treated by manual compression, intravenous oxytocin, methylergonovine maleate, and prostaglandins and then was observed for 10-15 minutes before applying a uterine flexion suture in the failed medical treatment cases. The patients were observed for vaginal bleeding, hematometra, and infection after operation. Uterine ultrasound scan results on days 1, 7, and 30 postoperation were also reviewed.

Results: Fifty-seven patients with uterine atony during cesarean delivery received the uterine flexion suture. The mean age of patients was 27.0 (15-44 years). Thirty-four patients were primipara. The indications for cesarean section were cephalopelvic disproportion in $27(47.4 \%)$ cases, and previous cesarean section in $11(19.3 \%)$ cases. Neither postoperative excessive bleeding nor hysterectomy was observed. There was no hematometra or serious postoperative complication after surgery. The estimated time for uterine flexion suture is only $2-3$ minutes and was very easy to perform.

Conclusion: Uterine flexion suture technique, which was modified from the B-Lynch suture, was inexpensive, quick, and effective in the treatment of atonic postpartum uterus in women undergoing cesarean section.

Keywords: B-Lynch, uterine atony, cesarean section, uterine compression suture, uterine flexion suture

\section{Introduction}

Uterine atony is common during both vaginal delivery and cesarean delivery. ${ }^{1}$ Without appropriate treatment, it can lead to severe postpartum hemorrhage and maternal mortality. Globally, uterine atony is the most common cause of postpartum hemorrhage, which is estimated to cause a women's death every 10 minutes around the world, especially in developing countries. ${ }^{2,3}$

Uterine atony usually is treated by medications such as oxytocin, ergometrine, misoprostol, or sulprostone ${ }^{4}$ and surgery in case of failed medical treatment. ${ }^{5}$ Surgical treatment for uterine atony include uterine artery ligation, internal iliac artery ligation, or hysterectomy. ${ }^{4}$ In case of uterine atony during cesarean section, $25 \%$ of the cases 
responded to conservative management by uterine massage and uterotonic agents and the others needed surgical intervention. ${ }^{6}$

In 1997, B-Lynch et $\mathrm{al}^{7}$ reported a uterine compression suture technique for the treatment of postpartum hemorrhage with a good result. This technique was practiced and modified by many centers around the world. ${ }^{8-14}$ Due to practical use of this technique, uterine compression suture had been reported to be used to prevent postpartum hemorrhage in case of uterine atony during cesarean section or high-risk cases such as chorioamnionitis, preeclampsia, prolonged labor, second-stage arrest, multiple gestation, and magnesium sulfate treatment with a good treatment result. ${ }^{6,14,15}$

However, the B-Lynch uterine compression suture needs a special wide curved needle and a long suture. Also, the uterus needs to be reopened to explore the intrauterine cavity, which takes time and is inconvenient. For this reason, we developed a new technique, which is less time consuming and is more convenient for the treatment of uterine atony during cesarean section (initially described by the second author) in the Department of Obstetrics and Gynecology of Udonthani Hospital, Thailand.

\section{Materials and methods}

Between January 2009 and December 2017, medical records of patients who had uterine atony during cesarean section operation and received a uterine flexion suture by the new technique, which derived from the B-Lynch uterine compression suture, were reviewed.

Uterine flexion suture technique was done by the following steps:

1. Patients received the low transverse cesarean section from obstetric indications.

2. After delivery of baby and placenta, 5-10 U of oxytocin was injected intramuscularly, uterine suture was done by atraumatic number 1 chromic catgut single layer, and uterine contraction was assessed by the surgeon. If uterine atony was detected, oxytocin intravenous, methylergonovine maleate (Methergin ${ }^{\circledR}$ ), and sulprostone (Nalador ${ }^{\circledR}$ ) were used step by step.

3. If the contraction was not improved after 10-15 minutes of medical treatment, the surgical intervention by uterine flexion suture was used.

4. The suture material was $75 \mathrm{~cm}$ atraumatic number 1 chromic catgut with $40 \mathrm{~mm}$ round needle.

5. The suture technique is (Figure 1) as follows:

a. Exteriorization of the uterus from the abdominal cavity is performed. b. The suture first begins at $1-2 \mathrm{~cm}$ below right inferior edge and 3-4 $\mathrm{cm}$ from the lateral border of the cesarean incision without reopening of the uterine cavity. This approach is suggested for a surgeon standing on the patient's right side.

c. The suture is then passed to the upper incision margin 1-2 cm above and $\sim 3-4 \mathrm{~cm}$ from the left lateral border, not too deep to avoid puncture through the posterior wall.

d. This is then fed anteriorly and vertically over the fundus and then passed back to posteriorly and downward to enter the posterior wall of uterus at the same level as the upper anterior entry point. The suture is placed horizontally at the midline of the uterus with $\sim 1-2 \mathrm{~cm}$ depth, not too deep to avoid puncture through anterior wall.

e. The suture is fed posteriorly and vertically over the fundus to lie anteriorly and vertically over the fundus on the left side as occurred on the right side. The needle is passed in the same fashion to the left side through the cesarean incision.

f. The uterus is held in anteflexion position by an assistant, then the suture is pulled under moderate tension to hold the uterus in the flexion position, and the suture is tied securely.

g. The uterus is placed back into the abdominal cavity, the bleeding points are checked and sutured, and then, the abdominal wall is closed layer by layer. (An additional video file shows this in more detail [Supplementary material].)

6. After the operation, the patients received oxytocin intravenous drip for at least 8 hours. The fundal height and blood loss were assessed 1 and 2 hours postoperation. The vital signs, fundal height, and lochia were assessed every day.

7. The ultrasonography was performed 24 hours and on days 7 and 30 postoperation to assess the uterus.

This retrospective study reviewed the medical records for age, gravida, parity, indication for cesarean section, preoperative tocolytics, estimated blood loss before and after suture, drug used for the treatment of atonic uterus, time of suture and operation, estimated blood loss in 24 hours, febrile morbidity, and sonographic finding taken 24 hours, 7 days, and 1 month after operation. The telephone interviews were performed to evaluate the postoperative fertility of the patients at the time of study.

This study was approved by the ethical research committee of Udonthani Hospital (no 22/2559). The retrospective 

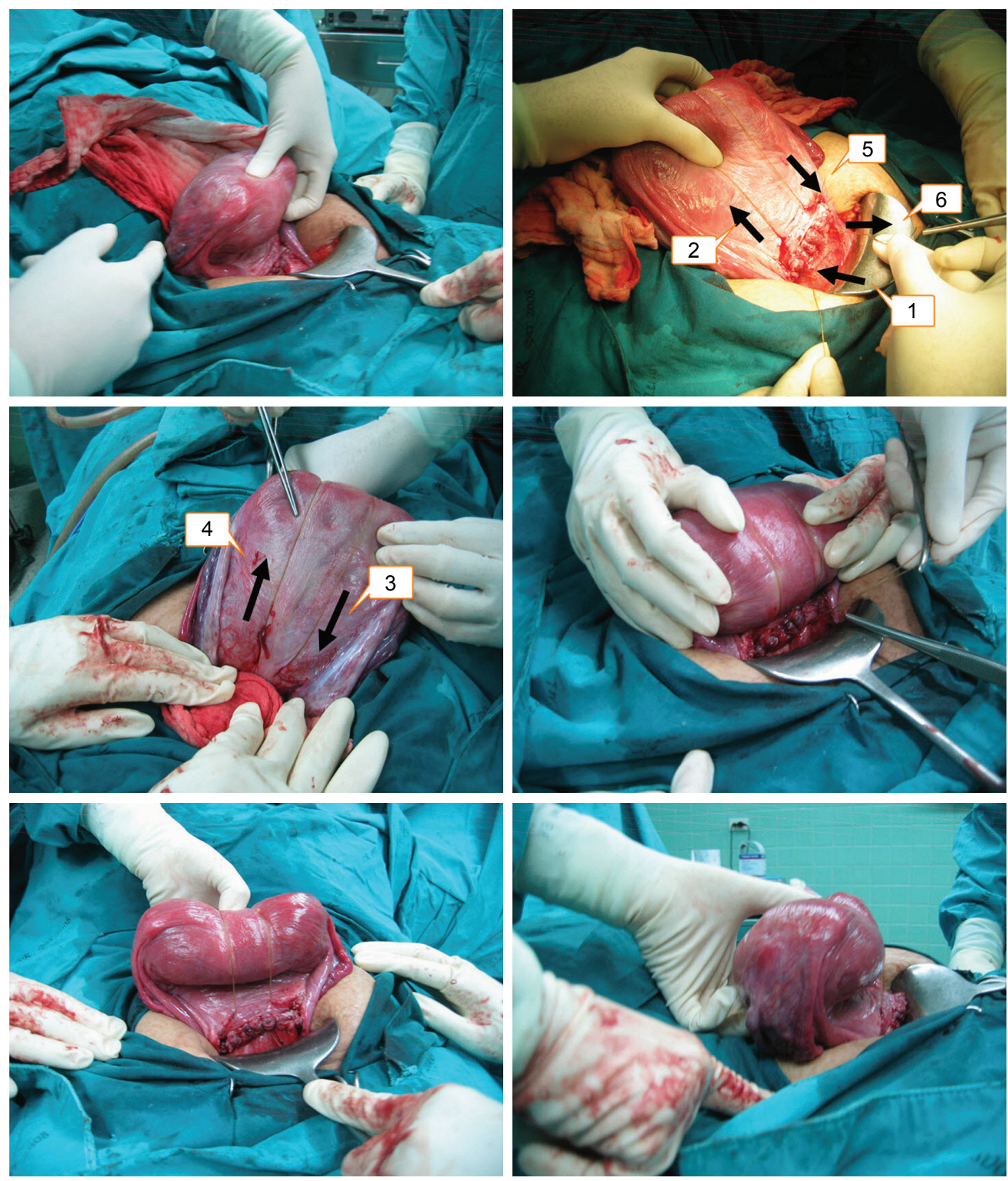

Figure I Uterine flexion suture technique.

Notes: (I) The suture first begins at I-2 cm below right inferior edge and $3-4 \mathrm{~cm}$ from the lateral border, (2) the suture is then passed to the upper incision margin I-2 cm above and $3-4 \mathrm{~cm}$ from the left lateral border, (3) it is entered the posterior wall of uterus at the same level as the upper anterior entry point, (4) the suture is placed horizontally at the midline of the uterus with $\sim 1-2 \mathrm{~cm}$ depth, and $(5$ and 6$)$ the needle is passed in the same fashion to the left side.

use of the patients' data was permitted by the director and ethical research committee of Udonthani Hospital. The ethics committee waived patient consent to review their medical records because the presentation of the data in this research was the summary data with de-identified individuals. All patients enrolled in this study provided their written informed consent. The parent or legal guardian provided their written informed consent for all patients younger than 18 years.

\section{Data analyses}

The descriptive statistics of the patients and the blood loss were presented as mean and standard deviation, such as age.
Categorical variables were presented as numbers and percentage. All statistical analyses were conducted using Stata13 (StataCorp LP, College Station, TX, USA).

\section{Results}

From January 2009 to December 2017, there were a total of 37,843 deliveries, of which 16,678 were cesarean deliveries (44.1\%). Fifty-seven patients undergoing cesarean section had uterine atony during their operation, which did not respond to medical treatment. These patients received the uterine flexion suture by the new technique, which was 
Table I Characteristics of patients

\begin{tabular}{ll}
\hline Characteristics & Number \\
\hline Total number of patients (cases) & 57 \\
Age (years), mean \pm SD (range) & $27.0 \pm 7 . I(15-44)$ \\
Gestational age, mean \pm SD (range) & $37.5+1.9(32-4 I)$ \\
Parity, $\mathrm{n}(\%)$ & \\
Primipara & $34(59.7)$ \\
Multipara & $23(40.3)$ \\
Indication, $\mathrm{n}(\%)$ & \\
Cephalopelvic disproportion & $27(47.4)$ \\
Previous cesarean section & $11(19.3)$ \\
Twin pregnancy & $6(10.5)$ \\
Fetal distress & $5(8.8)$ \\
Preeclampsia & $3(5.3)$ \\
Others & $5(8.8)$ \\
Risk factors of uterine atony, $\mathrm{n}(\%)$ & \\
Obesity & $34(59.7)$ \\
Induction or augmentation of labor & $14(24.6)$ \\
Prolonged labor & $12(21.1)$ \\
Multifetal pregnancy & $6(10.5)$ \\
Received magnesium sulfate & $6(10.5)$ \\
Others & $6(10.5)$ \\
Uterotonic agents used, $n(\%)$ & \\
Oxytocin & $57(100)$ \\
Methylergonovine maleate (Methergin $\left.{ }^{\circledR}\right)$ & $47(82.5)$ \\
Sulprostone (Nalador $\left.{ }^{\circledast}\right)$ & $37(64.9)$ \\
\hline
\end{tabular}

modified from the B-Lynch uterine compression suture. The patients' characteristics are shown in Table 1.

Postpartum hemorrhage was diagnosed in some cases; however, in most cases, the uterine flexion suture was done after uterine atony but before severe blood loss occurred (Table 2).

The chromic catgut number 1 was used in all cases, and the estimated time for this operation was 2-3 minutes. No postpartum hysterectomy was needed in all cases. No postoperative hematometra was detected from ultrasonography. The early postoperative complication was postoperative febrile

Table 2 Results of treatment

\begin{tabular}{ll}
\hline Results & Cases \\
\hline Uterine preservation, $\mathrm{n}(\%)$ & $57(\mathrm{I00})$ \\
Estimated blood loss (mL), mean \pm SD (range) & $468.4 \pm 274.5$ \\
& $(200-1,500)$ \\
Estimated blood loss $>500 \mathrm{~mL}, \mathrm{n}(\%)$ & $14(24.6)$ \\
Postpartum hemorrhage $(>\mathrm{I}, 000 \mathrm{~mL}), \mathrm{n}(\%)$ & $5(8.8)$ \\
Complication, $\mathrm{n}(\%)$ & \\
$\quad$ Febrile morbidity & $5(8.8)$ \\
Fertility after procedure, $\mathrm{n}(\%)$ & \\
$\quad$ Tubal resection & $22(38.6)$ \\
$\quad$ Contraception & $13(22.8)$ \\
Pregnancy & $4(7.0)$ \\
No pregnancy & $9(15.8)$ \\
Loss to follow-up & $9(15.8)$ \\
\hline
\end{tabular}

morbidity in five cases $(8.8 \%)$, which responded to antibiotics treatment. All patients were discharged from the hospital in 3-4 days postoperation, and no postoperative complication was detected at 7 and 30 days postpartum (Table 2).

The patient's postoperative fertility function was assessed by the researchers in a telephone interview. Tubal resection was done with cesarean section in 22 cases because the patients requested sterilization preoperatively. Of the remainder, 26 cases were contacted by telephone interview, four cases had been pregnancy after the procedure, and 13 cases used contraception. No late complication was founded from the telephone interview (Table 2).

\section{Discussion}

Uterine atony is the most common cause of postpartum excessive bleeding, which is also the most common cause of maternal death in developing countries. ${ }^{6,16,17}$ The early, aggressive, and coordinated intervention by health care professionals to minimize the blood loss is the key factors to avoid a tragic outcome. ${ }^{5}$ Uterine atony during cesarean section is a common complication because many risk factors are found in cesarean section patients such as prolonged labor and multifetal pregnancy.

Uterine compression suture is an effective way to treat uterine atony. It was first reported by B-Lynch et $\mathrm{al}^{7}$ in 1997 with an average success rate of $97 \%$, varying from 76 to $100 \% .{ }^{18} \mathrm{~B}$-Lynch also described in his first report that "costeffectiveness of this procedure may encourage developing countries to consider its application where necessary both for prophylactic and therapeutic purposes". Some reports used this technique for prophylaxis in risk cases of postpartum hemorrhage such as Jehovah's witness with triplets, ${ }^{19}$ eclampsia, multiple pregnancy, chorioamnionitis, and prolonged second-stage and uterine atony after delivery. ${ }^{15}$

In 2010, the author reported this modified B-Lynch technique in 12 cases of uterine atony during cesarean section without complications. ${ }^{20}$ This study reported the long-term use of this technique in our 9 years of experience. The uterine flexion suture, which is modified from the B-Lynch technique, was used in both treatment and prophylaxis for postpartum hemorrhage in case of uterine atony during cesarean section. Most common indication in this study was cephalopelvic disproportion, which might risk uterine atony after birth. ${ }^{4}$

The reasons for modification of the B-Lynch technique in our situation were first that the original uterine compression suture needs to reopen the uterus to suture through the uterine cavity. However, in this study, the uterine atony was 
initially treated by medical treatment and suturing the uterus was done while waiting for the effect of medical treatment. The reopening of the uterus might increase blood loss and be time consuming.

Moreover, the suture material and needle are the important reasons for our modification of the B-Lynch technique. The original B-Lynch technique and other modified techniques such as Hayman and $\mathrm{Cho}^{7,10,21}$ need a special long, curved needle for suture through the anterior and posterior wall of the uterus. In our situation, cesarean section in the obstetric operating room is difficult to find this special needle so the use of chromic catgut number 1 with $40 \mathrm{~mm}$ needle, which is our routine suture material for myometrial closure in cesarean section, is quite easy and convenient. This technique can be performed in only 2 or 3 minutes compared with $9.3 \pm 2.8$ minutes using the B-Lynch technique. ${ }^{22}$

Our technique does not reopen the uterine cavity. Therefore, the transverse posterior lower uterine stitch suture must not be too deep until it passes to the anterior uterine muscular wall, to prevent the obstruction of blood and lochia that will cause infection or hematometra. ${ }^{23}$ The main force to stop bleeding in our modified technique came from flexion of the uterus, not from direct compression of the uterus by suture material. This flexion compresses the anterior and posterior uterine walls together, and the suture material is functional only to hold the uterus in that position so the suture material does not need to be tied tightly to create direct pressure on the uterus as in the B-Lynch technique, which can cause necrosis of myometrium or deformity of the uterus. ${ }^{24-27}$

The flexion of uterus also allows us to tie the uterus with only a $75 \mathrm{~cm}$ length suture. However, we were concerned about the flow of blood and lochia postpartum so we followed all cases by ultrasonography on the first, seventh, and thirtieth days postpartum. We also recommend to those who will use this uterine flexion technique to reexamine the patients by ultrasonography to prevent complications.

The results of postpartum ultrasound examination were normal in all cases without hematometra or other complications detected. Some cases received repeated cesarean delivery in their next pregnancy after this uterine flexion suture. However, the fertility function and complications after this technique need further long-term evaluation.

The limitation of this study was most cases were done in uterine atony after the failure of medical treatment but before the severe postpartum blood loss occurred, so the effectiveness of this procedure for the treatment of severe bleeding was not clearly demonstrated.

\section{Conclusion}

The uterine flexion suture technique, which is modified from the B-Lynch operation, was inexpensive, quick, easy to perform, and effective in the treatment of atonic postpartum uterus in women undergoing cesarean section.

\section{Acknowledgments}

We gratefully acknowledge Dr Thammanoon Wisittanawat, Director of Udonthani Hospital, for grant support. This study was presented at the 69th Annual Congress of the Japan Society of Obstetrics and Gynecology as an oral presentation. The abstract was published in http://www.myschedule. jp/jsog2017/search/detail program/id:190.

\section{Disclosure}

The authors report no conflicts of interest in this work.

\section{References}

1. Sheldon WR, Blum J, Vogel JP, et al. Postpartum haemorrhage management, risks, and maternal outcomes: findings from the World Health Organization Multicountry Survey on Maternal and Newborn Health. BJOG. 2014;121(Suppl 1):5-13.

2. Weeks A. The prevention and treatment of postpartum haemorrhage: what do we know, and where do we go to next? BJOG. 2015;122(2): 202-210.

3. Edhi MM, Aslam HM, Naqvi Z, Hashmi H. "Post partum hemorrhage: causes and management". BMC Res Notes. 2013;6(236):236.

4. Cunningham FG, Leveno KJ, Bloom SL, Dashe JS, Hoffman BL, Casey BM, et al. Williams Obstetrics. 25th ed. New York: McGraw Hill 2018.

5. Abdul-Kadir R, Mclintock C, Ducloy AS, et al. Evaluation and management of postpartum hemorrhage: consensus from an international expert panel. Transfusion. 2014;54(7):1756-1768.

6. Nahar SNS, Khannam M. Simple technique of uterine compression sutures for prevention of primary postpartum hemorrhage during caesarian section. PakJ Med Sci. 2010;26:319-323.

7. B-Lynch C, Coker A, Lawal AH, Abu J, Cowen MJ. The B-Lynch surgical technique for the control of massive postpartum haemorrhage: an alternative to hysterectomy? Five cases reported. Br J Obstet Gynaecol. 1997;104(3):372-375.

8. El-Hamamy E, B-Lynch C. A worldwide review of the uses of the uterine compression suture techniques as alternative to hysterectomy in the management of severe post-partum haemorrhage. J Obstet Gynaecol. 2005;25(2):143-149.

9. Bhal K, Bhal N, Mulik V, Shankar L. The uterine compression suturea valuable approach to control major haemorrhage at lower segment caesarean section. J Obstet Gynaecol. 2005;25(1):10-14.

10. Cho JH, Jun HS, Lee CN. Hemostatic suturing technique for uterine bleeding during cesarean delivery. Obstet Gynecol. 2000;96(1): $129-131$.

11. Ghezzi F, Cromi A, Uccella S, Raio L, Bolis P, Surbek D. The Hayman technique: a simple method to treat postpartum haemorrhage. BJOG. 2007;114(3):362-365.

12. Pereira A, Nunes F, Pedroso S, Saraiva J, Retto H, Meirinho M. Compressive uterine sutures to treat postpartum bleeding secondary to uterine atony. Obstet Gynecol. 2005;106(3):569-572.

13. El-Sokkary M, Wahba K, El-Shahawy Y. Uterine salvage management for atonic postpartum hemorrhage using "modified lynch suture". BMC Pregnancy Childbirth. 2016;16(251):251. 
14. Kaya B, Guralp O, Tuten A, Unal O, Celik MO, Dogan A. Which uterine sparing technique should be used for uterine atony during cesarean section? The Bakri balloon or the B-Lynch suture? Arch Gynecol Obstet. 2016;294(3):511-517.

15. Vachhani MVA. Prophylactic B-Lynch suture during emergency caesarean section in women at high risk of uterine atony: a pilot study. The Internet Journal of Gynecology and Obstetrics. 2006;7(1).

16. World Health Organization. WHO Recommendations for the Prevention and Treatment of Postpartum Hemorrhage. Geneva: WHO; 2012.

17. World Health Organization. Maternal Mortality a Global Fact Book. Geneva: WHO; 1991.

18. Matsubara S, Yano H, Ohkuchi A, Kuwata T, Usui R, Suzuki M. Uterine compression sutures for postpartum hemorrhage: an overview. Acta Obstet Gynecol Scand. 2013;92(4):378-385.

19. Kalu E, Wayne C, Croucher C, Findley I, Manyonda I. Triplet pregnancy in a Jehovah's witness: recombinant human erythropoietin and iron supplementation for minimising the risks of excessive blood loss. BJOG. 2002;109(6):723-725.

20. Songthamwat M. Modified B-Lynch technique for prevention of primary postpartum hemorrhage during cesarean section. Udonthani Hospital Medical Journal. 2010;18(3):41-46.
21. Hayman RG, Arulkumaran S, Steer PJ. Uterine compression sutures: surgical management of postpartum hemorrhage. Obstet Gynecol. 2002; 99(3):502-506

22. Al Riyami N, Hui D, Herer E, Nevo O. Uterine compression sutures as an effective treatment for postpartum hemorrhage: case series. AJP Rep. 2011;1(1):047-052.

23. Ochoa M, Allaire AD, Stitely ML. Pyometria after hemostatic square suture technique. Obstet Gynecol. 2002;99(3):506-509.

24. B-Lynch C. Partial ischemic necrosis of the uterus following a uterine brace compression suture. BJOG: An International Journal of Obstetrics and Gynaecology. 2005;112(1):126-127.

25. Joshi VM, Shrivastava M. Partial ischemic necrosis of the uterus following a uterine brace compression suture. BJOG. 2004;111(3): 279-280.

26. Treloar Ej AR, Andrews HS. Bailey JI Uterine necrosis following B-Lynch suture for primary postpartum hemorrhage. BJOG. 2006;4: 486-488.

27. Begum J, Pallave P. Ghose S. B-Lynch: a technique for uterine conservation or deformation? A case report with literature review. J Clin Diagn Res. 2014;8(4):OD01-OD03.
International Journal of Women's Health

\section{Publish your work in this journal}

The International Journal of Women's Health is an international, peerreviewed open-access journal publishing original research, reports, editorials, reviews and commentaries on all aspects of women's healthcare including gynecology, obstetrics, and breast cancer. The manuscript management system is completely online and includes

\section{Dovepress}

a very quick and fair peer-review system, which is all easy to use. Visit http://www.dovepress.com/testimonials.php to read real quotes from published authors. 